\title{
Characterization of Ultrasonic Transducers \\ Using Pattern Recognition Techniques
}

Kansas City Division

J. W. Ekis

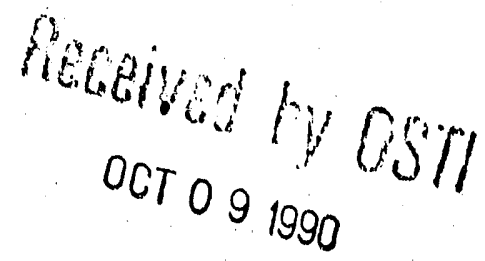

KCP-613-4426

Published September 1990

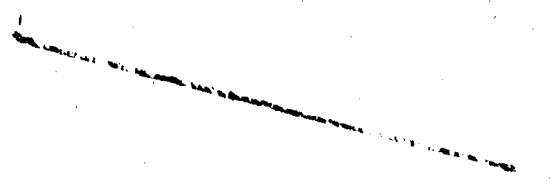

Prepared for the United States Department of Energy Un ar Contract Number DE-AC04-76-DP00613.

\section{Allied-Signal Aerospace Company}

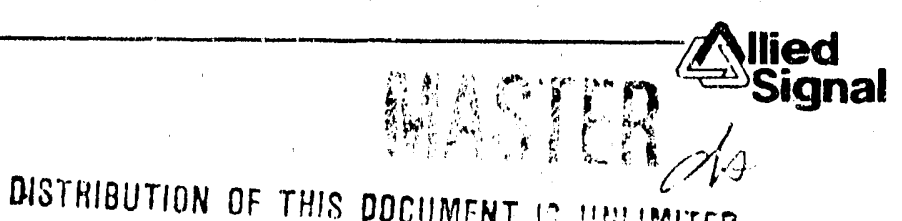


This report was prepared as an account of work sponsored by an agency of the United States Government. Neither the United States Government nor any agency thereof, nor any of their employees, makes any warranty, express or implied, or assumes any legal liability or responsibility for the accuracy, completeness, or usefulness of any information, apparatus, product, or process disclosed, or represents that its use would not infringe privately owned rights. Reference herein to any specific commercial product, process, or service by trade name, trademark, manufacturer, or otherwise, does not necessarily constitute or imply its endorsement, recommendation, or favoring by the United States Government or any agency thereof. The views and opinions of authors expressed herein do not necessarily state or reflect those of the United States Government or any agency thereof.

Printed in the United States of America.

This report has been reproduced from the best available copy.

Available to DOE and DOE contractors from the Office of Scientific and Technical Information, P.O. Box 62, Oak Ridge, Tennessee 37831; prices available from (615) 776-8401, FTS 626-8401.

Available to the public from the National Technical Information Service, U.S. Department of Commerce, 5285 Port Royal Rd., Springfield, Virginia 22161.

Price Code: Printed Copy A02 Microfiche A01 
$\mathrm{KCP}-613-4426$

Distribution Category UC-701

\author{
KCP $--613-4426$
}

CHARACTERIZATION OF ULTRASONIC TRANSDUCERS

DE9 I 000580

USING PATTERN RECOGNITION TECHNIQUES

J. W. Ekis

Publishec September 1990

Manuscript submitted to 1990 Fall American Society for Nondestructive Testing Conference, sponsored by American Society for Nondestructive Testing, Seattle, Washington, Dctober 10, 1990.

Technical Communications

Kansas City Division 


\title{
CHARACTERIZATION OF ULTRASONIC TRANSDUCERS USING PATTERN RECOGNITION TECHNIQUES
}

\author{
J. W. Ekis \\ Allied-Signal Inc. \\ Kansas City Division" \\ P. O. Box 419159, ME49 \\ Kansas City, MO 64141 \\ (816) $997-4830$ \\ M. S. Obaidat and S. A. Bleha \\ Department of Electrical and Computer Engineering \\ University of Missouri-Columbia, Truman Campus \\ 600 W. Mechanic \\ Independence, MO 64050 \\ (816)276-1276/(816)276-1278
}

\begin{abstract}
This paper describes an altomated method for characterizing ultrasonic transducers. A computer based test system will collect test data for a given transducer. This data set is then subjected to a pattern recognition algorithm. The results from this classification will place the transducer in a group of similar units. All the transducers in a group will have similar performance characteristics.
\end{abstract}

\section{INTRODUCTION}

The importance of having a well characterized ultrasonic transducer has been discussed in a significant amount of literature ${ }^{1-5}$. In order to fully understand the information collected by an ultrasonic test system, the test probe must be fully understood as well ${ }^{6}$. This involves quantifying such parameters as focal length, focal spot diameter, center frequency, bandwidth, insertion loss, cross-sectional uniformity, etc. This paper describes an automated system that collects this pertinent data for ultrasonic transducers.

Pattern recognition has also been successfully used in the ultrasonic testing field ${ }^{7-9}$. However, this work focuses on interpreting the resulting signals from a test specimen. This paper will report the results of using these pattern recognition techniques on the data collected from the characterized transducers. This will sort transducers of like properties into groupings. Transducers in a group should have similar testing properties and thus similar test results.

\footnotetext{
Operated for the U.S. Dept. of Energy under contract number DE-AC04-76-DP00613.
} 


\section{APPROACH}

Based on the needs of our laboratory, a set of characteristics to be tested were developed. They include the following: focal length, slope of near field and far field amplitude, insertion loss, center frequency, peak frequency, bandwidth, focal spot diameter, focal spot length, beam uniformity, and impulse response. Once these parameters were established, a computer controlled data acquisition syster 1 was created to collect information for over 200 transducers.

Figure 1 shows a block diagram of the system. The scanning segment consisted of an immersion tank with three orthogonal motorized axes of motion. This scanner is run by a programmable controller that is interfaced to the computer via the IEEE 488 bus. A pulser/receiver rated to $50 \mathrm{MHz}$ is used to energize the transducer. Also built into the pulser unit is a gated peak detector. The marked RF signal produced is sent to a $1 \mathrm{GHz}$ digitizing oscilloscope which connects to the computer via the IEEE 488 bus also. The gated RF signal is sent to a $2.9 \mathrm{GHz}$ digitizing spectrum analyzer which in turn is connected to the computer via the IEEE 488 bus. The computer workstation consists of a $30 \mathrm{MHz}$ 68030 processor with a $30 \mathrm{MHz} 68882$ math coprocessor with a $2 \mathrm{D}$ color image processing engine. The computer has over 750 Mbytes disk storage and 8 Mbytes of RAM. The system uses the UNIX operating system, but the software is written in BASIC. All the data collected is presented on the $1280 \times 1024$ color CRT. Each graph is stored as a bit map and can be dumped via a batch process to a 180 dpi color ink jet printer. The software for the system ULSUR, Ultrasonic Laboratory Search Unit Recorder, was written in house.

Once developed, this system was used to colleat the test information for over 200 different focused immersion transducers. All the data sets are stored on the system's hard disks for instant retrieval. A back up copy was also saved to tape cartridges. The data was also dumped to the color printer and this physical record is available to the engineers and technologists when developing a new test procedure. It also is useful when the original transducer has worn out and a near exact duplicate is required. All of these transducers

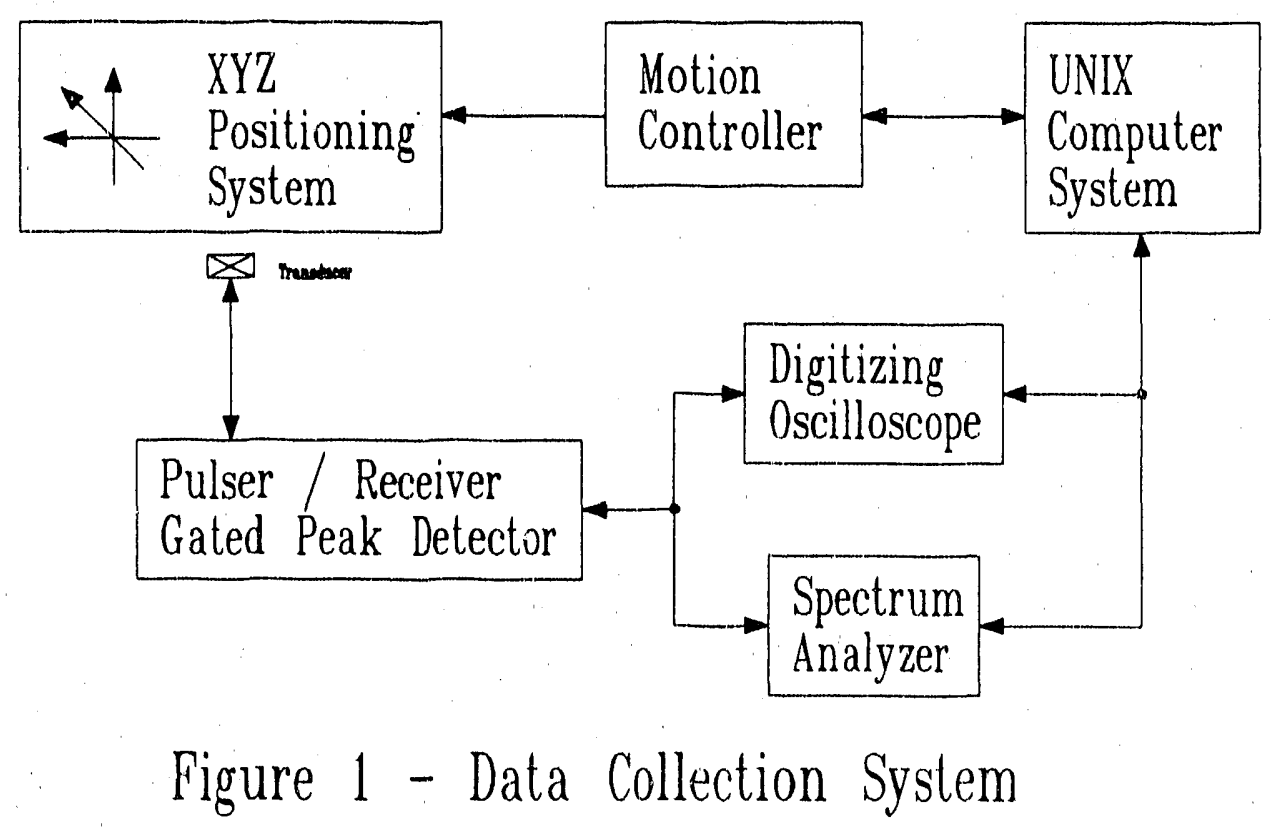


have been grouped into like units. This was done by applying some of the standard pattern recognition algorithms to the test data collected by ULSUR.

Two different approaches will be tried to characterize the data sets. One uses a sample set of transducers as training data and groups the remaining transducers into these norms. The other technique to be used will not have any training data, but sorts all the transducers into as many groups as necessary. Some data compression techniques will also be applied in an attempt to reduce the number of variables required to separate the transducers into their respective groups.

\section{CONCLUSION}

By applying conventional pattern recognition algorithms to classify the data collected from the computer controlled characterization sysrem, ultrasonic transducers can be sorted in to groups with similar properties. This will provide the information necessary to properly configure an ultrasonic test system for optimum test results. This system can also be used to observe when a given transducer has begun to wear. The final work on this project is under way.

\section{REFERENCES}

1. C. H. Chen, Tutorial on Signal Processing and Pattern Recognition in Nondestructive Evaluation of Materials, Proc. of $12^{\text {th }}$ World Conference on Non-Destructive Testing. Amsterdam, The Netherlands, April, 1989. pp. 845-850.

2. E. B. Miller and D. G. Eitzen, Ultrasonic Transducer Characterization at the NBS, IEEE Transactions on Sonics and Ultrasonics, January 1979. pp. 28-37.

3. R. Lal and D. K. Das-Gupta, Characterization of Ultrasonic Transducers, IEEE Transactions on Electrical Insulation, June 1989. pp. 473-480.

4. M. Auphan, R. H. Coursant, and C. Méquio, Ultrasonic Transducer Characterization by Means of a Spherical Target, Philips Journal of Research, Vol 4/5/6, 1981. pp. 263-288.

5. ASTM E 1065-87a, Standard Guide for Evaluating Characteristics of Ultrasonic Search Units, 1987.

6. P. G. Kenny, J. J. Gruber, and J. M. Smith, Uttrasonic Transducer Characterization, Materials Evaluation, June 1987. pp. 730-735.

7. S. F. Burch, Automated Characterization of Welding Defects using Ultrasonic Imaging and Pattern Recognition Techniques, Proc. of $4^{\text {th }}$ European Conference on Non-Destructive Testing, September 1987. pp. 531-539.

8. M. F. Insana, R. F. Wagner, B. S. Garra, R. Momenan, and T. H. Shawker, Supervised Pattern Recognition Techniques in Quantitative Diagnostic Ultrasound, Journal of Clinical Engineering, November 1988. pp. 447-454.

9. J. K. Bryan, Pattern Recognition Techniques Applied to Flat-Bottomed Holes, USAF ASEE Summer Faculty Research Program, September 1975. pp. 19-1 to 19-19. 

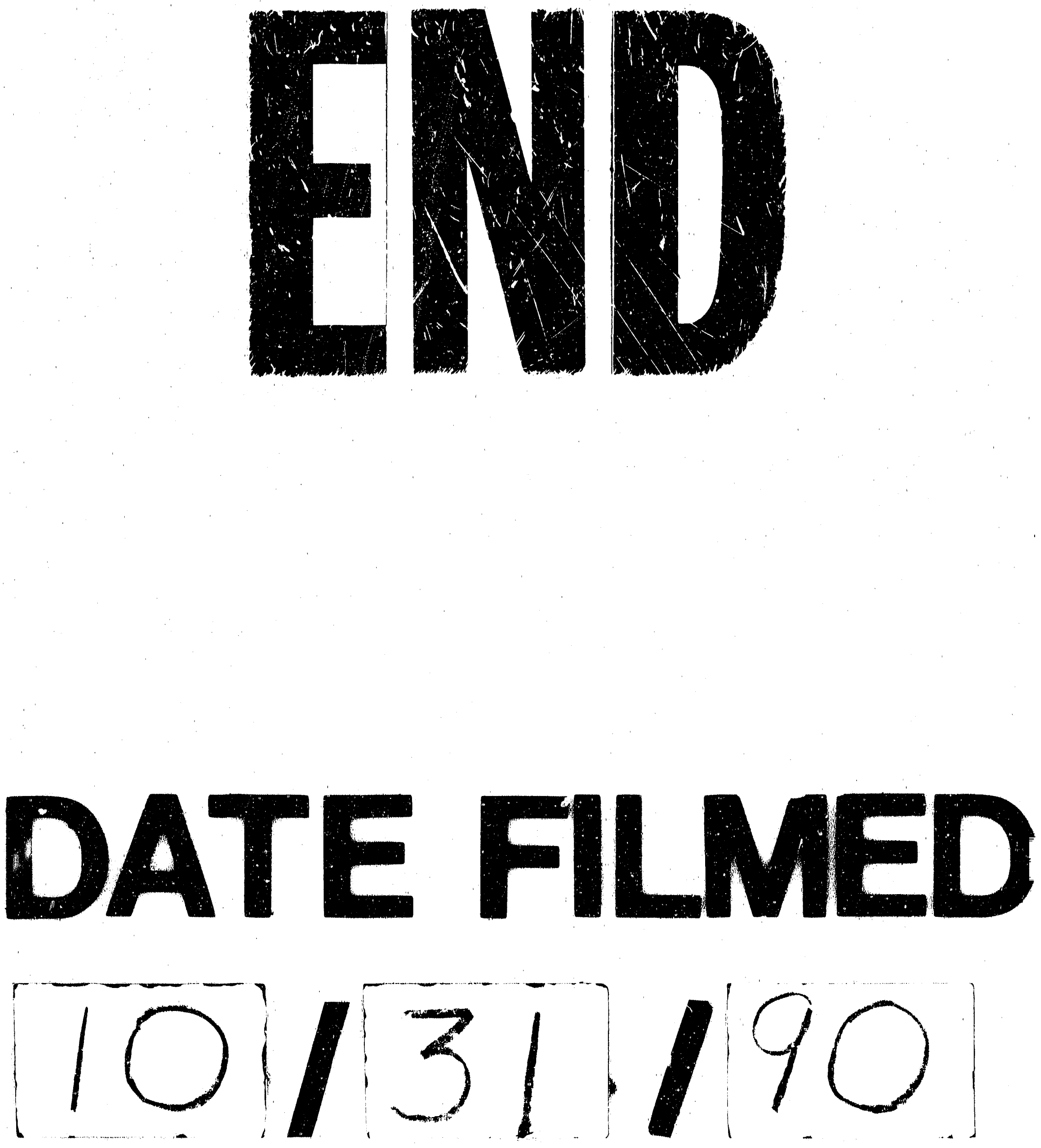
